\title{
Male Sex May Be the Defining Factor in Predicting Susceptibility to and Severity of SARS-CoV-2 Infection: A Case Series
}

\author{
Authors: \\ *Nafisha Aishah Ali, ${ }^{1}$ Sakthi Swaroopini Gautham, ${ }^{1}$ Frank A. Agnone ${ }^{2}$ \\ 1. International American University College of Medicine, Vieux Fort, St. Lucia \\ 2. Internal Medicines Physicians Associates, Phoenix, Arizona, USA \\ *Correspondence to nali@iau.edu.lc
}

Disclosure: $\quad$ The authors have declared no conflicts of interest.

Acknowledgements: The authors would like to thank Dr Frank LoVecchio for the guidance he provided in the editing and proofreading process of this paper. The authors would also like to thank the staff at Internal Medicine Physicians Associates who assisted in obtaining patient histories, patient testing, and acquiring of patient electronic health records.

Received:

26.05 .20

Accepted:

30.06 .20

Keywords:

ACE2 enzyme, COVID-19, coronavirus infections, severe acute respiratory syndrome (SARS) virus, $\mathrm{X}$-linked genes.

Citation:

EMJ Microbiol Infect Dis. 2020;DOI/10.33590/emjmicrobiolinfectdis/20-00136.

\section{Abstract}

Severe acute respiratory syndrome coronavirus-2 (SARS-CoV-2) is the virus that causes the coronavirus disease (COVID-19). This paper will describe a series of three confirmed cases of COVID-19 and use patterns observed in these cases to discuss the association of this infection with male sex through different mechanisms linked to the $X$ chromosome. The patients' symptoms and diagnostic testing are reviewed, while also focussing on the illness status of their immediate family members. It is known that the $X$ chromosome is linked to SARS-CoV-2 viral infectivity through the androgen receptor gene which is located on the $\mathrm{X}$ chromosome, and that angiotensin-converting enzyme 2 has an unconfirmed pattern of X-linked inheritance of its allelic variants, some of which are known to afford stronger binding affinity to SARS-CoV-2. However, there are no studies that investigate these factors in combination with each other and how this combination predicts disease outcome in males versus females, providing a more concrete explanation for the observed pattern that suggests this disease leads to poorer disease outcomes in males. Investigation of these factor combinations will allow for greater understanding of the epidemiology of this virus and the development of more accurate guidelines for the prevention, diagnosis, management, and prognosis of SARS-CoV-2 infection.

\section{INTRODUCTION}

Severe acute respiratory syndrome coronavirus 2 (SARS-CoV-2) is the virus that causes the coronavirus disease (COVID-19). ${ }^{1}$ SARS-CoV-2 is

a coronavirus composed of four major structural proteins which include spike glycoprotein, small envelope glycoprotein, membrane glycoprotein, and nucleocapsid protein, among other accessory proteins. ${ }^{2}$ Studies show that the average incubation period of the virus is 
5-6 days, however this can be up to 14 days. ${ }^{3}$ People infected with SARS-CoV-2 are thought to be at low risk of transmission to others 10 days after symptom onset, provided that they have been without fever or respiratory symptoms for 3 days. ${ }^{4}$

Signs and symptoms of COVID-19 include fever, cough and fatigue, shortness of breath or difficulty breathing, chest pain, chills, diarrhoea, loss of taste or smell, and headaches., ${ }^{1,5,6}$ SARSCoV-2 is now known to induce an immune system hyperactivity, termed a 'cytokine storm', which causes severe illness. ' Severe illness results in severe pneumonia and acute respiratory distress syndrome (ARDS). ${ }^{8}$ SARS-CoV- 2 has also recently been shown to cause various arterial and venous thrombotic events such as deep vein thrombosis, pulmonary embolism, ischaemic stroke, and myocardial infarction, as well as microvascular thrombotic events. ${ }^{9}$ This phenomenon has been termed COVID-19associated coagulopathy and is thought to be an acquired syndrome that arises because of the ability of SARS-CoV-2 to induce Virchow's triad of hypercoagulability, haemodynamic changes, and endothelial dysfunction. ${ }^{9}$

The proposed transmission mechanism of SARSCoV-2 is airborne and droplet transmission; however, there is new evidence which supports possible faecal-oral transmission as well. ${ }^{10}$ Recent data has demonstrated that male patients, patients who are $\geq 65$ years of age, and patients with underlying chronic illnesses including cardiovascular disease, diabetes, chronic respiratory diseases, hypertension, and cancer are more likely to present with severe illness. ${ }^{11,12}$

The spike protein of SARS-CoV-2 is recognised by the human angiotensin-converting enzyme 2 (ACE2), which allows the virus to infect human cells ${ }^{13}$ The human ACE2 gene is encoded by the $X$ chromosome. ${ }^{14}$ Furthermore, the $X$ chromosome also encodes the human androgen receptor $(A R)$ gene, which is also associated with SARS-CoV-2 infectivity. ${ }^{15}$

Diagnostic testing for COVID-19 includes PCR, which detects viral RNA in samples from the upper respiratory tract (including saliva); rapid antibody tests which qualitatively detect serum IgM and IgG to SARS-CoV-2; ELISA, which qualitatively detects serum IgG; and antigen tests. $^{8}$ Chest X-rays typically show bilateral, multifocal opacities and chest CT typically shows bilateral, peripheral ground-glass opacities with later development of areas of consolidation; however, diagnostic imaging may be normal in the early stages of disease, or show abnormalities in asymptomatic disease. ${ }^{8}$

The U.S. Food and Drug Administration (FDA) advises taking preventative measures and utilising supportive care which includes administering supplemental oxygen and mechanical ventilation when required. ${ }^{16}$ However, there are presently ongoing clinical trials worldwide that evaluate the effectiveness of existing drugs to treat COVID-19, with an aim to find a cure. These trials include the multinational Solidarity trial conducted by the World Health Organization (WHO), the RECOVERY trial conducted by the University of Oxford in the UK, and the web-based Discovery trial conducted by INSERM in France. ${ }^{17-19}$ According to the Centers for Disease Control and Prevention (CDC), standard preventative methods to avoid infection with SARS-CoV-2 include frequent and thorough handwashing, maintaining a physical distance of at least 6 feet, wearing masks, and disinfecting frequently touched surfaces and objects regularly. ${ }^{20}$ Although there is no approved vaccine against SARS-CoV-2 thus far, vaccine trials are ongoing. Of note is the COVOO2 trial in Oxford, UK, which is a Phase II/III trial testing the ChAdOX1 nCoV-19 vaccine candidate. ${ }^{21}$

As of early May 2020, the preliminary hospitalisation rate for persons with laboratoryconfirmed COVID-19 in the USA was 50.3 per 100,000, alongside >1.5 million emergency department (ED) visits for COVID-like-illness and $>1.2$ million ED visits for influenza-likeillness; it is likely that these numbers are much higher, but have been under-reported by many institutions. 22,23 To date, there have been approximately 120,000 deaths caused by COVID-19 in the USA and approximately 42,000 deaths in the UK. ${ }^{24}$

This paper will describe a series of three confirmed cases of COVID-19 and use patterns observed in these cases to discuss the association of this infection with male sex through different mechanisms linked to the $\mathrm{X}$ chromosome. 


\section{CASE DESCRIPTION}

\section{Case One}

A 49-year-old female with a history of wellcontrolled, intermittent asthma reported limited travel within the USA but admitted to being visited by family members who had travelled from across the globe in December 2019. The patient's last reported illness in December 2019 comprised fevers, chills, fatigue, muscle aches, nonproductive cough, headaches, and diarrhoea. The patient tested positive on the PCR test for SARS-Cov-2 RNA, and positive on the rapid antibody test for IgG antibodies against SARSCoV-2 in mid-March 2020. The patient remained positive for SARS-CoV-2 RNA 3 days after the initial testing. Nine days after the initial testing, the patient had a negative PCR test. The patient's two children, a 3-year-old female and a 6-yearold male, also experienced similar symptoms during the same time period in December 2019. The patient's other family members (husband, and son aged early 20s) did not have similar symptoms. All of the patient's family members tested negative for SARS-CoV-2 RNA and antibodies against SARS-CoV-2. The patient had received the annual influenza vaccine for 2019-2020 in the autumn of 2019. The patient was a lifetime non-smoker.

\section{Case Two}

A 62-year-old male, with a history of hyperlipidaemia and a few prior episodes of pneumonia, reported extensive travel throughout the USA for work in January and February of 2020. The patient reported the onset of illness as mid-February 2020 while on a trip to Florida. The patient initially developed a fever which lasted 3 days and a cough which lasted 2 weeks. $\mathrm{He}$ also developed wheezing, difficulty breathing at rest, and an inability to inhale deeply early in the disease course. The patient visited the ED of a Florida hospital on Day 5 of their illness where they were given a course of azithromycin, an albuterol inhaler, and a course of steroids. The patient's chest X-ray at the time showed no abnormal changes, and rapid testing for influenza $A$ and $B$ was negative. The patient was not tested for SARS-CoV-2 during their illness. The patient reported an overall loss of $6.8 \mathrm{~kg}$ during their illness and improvement in symptoms by Day 8 of illness. In mid-March, 5 weeks after the initial onset of symptoms, the patient tested positive via PCR for SARS-CoV-2 RNA and positive via rapid antibody test for IgG against SARS-CoV-2. Six weeks after the initial onset of symptoms the patient tested negative on the PCR test for SARS-CoV-2. The patient had received the annual influenza vaccine for 2019-2020. The patient is a lifetime non-smoker and interacted with their 29-year-old son and 32-year-old-daughter during their illness. His daughter subsequently tested positive via PCR for SARS-CoV-2 and his son tested negative.

\section{Case Three}

A 32-year-old female, the daughter of the patient described in Case Two, had no significant medical history. The patient became symptomatic in mid-February. The patient was the caregiver for their symptomatic father who was not tested for COVID-19 at the ED in February 2020. The family is uncertain about whether the father had COVID-19 at that time. The patient had a cough, shortness of breath at rest, anosmia, and a fever as high as $38.3{ }^{\circ} \mathrm{C}$ which lasted 4 days. Five weeks after their reported symptoms, they tested positive via PCR for SARS-CoV-2 RNA and negative via the rapid antibody test for IgG against SARS-CoV-2. The patient subsequently tested negative on ELISA for IgG against SARS-CoV-2. The patient had received the annual influenza vaccine for 2019-2020 and is a lifetime non-smoker.

\section{DISCUSSION}

The ACE2 gene was discovered in the year 2000 and is located on the X chromosome at $p 22.2$, with the highest expression in the gastrointestinal tract, kidneys, testes, heart, and lungs. ${ }^{14,25}$ ACE2 is a transmembrane carboxypeptidase with a known function of converting angiotensin I to angiotensin II in alveolar epithelium, which results in systemic vasoconstriction and thereby regulates blood pressure. ${ }^{26}$ The various other functions of ACE2 expression in other tissues continue to be studied. There are also known correlations between allelic variants coding for ACE2 and the severity of ARDS in humans with SARS-CoV infection. ${ }^{27}$ It remains unknown which allelic variants of ACE2 are expressed in the patients presented in this case series, as genetic testing is not readily available. 
SARS-CoV viral structure, mechanisms of infection, and the illness it causes have been thoroughly studied. Comparison of SARS-CoV to the novel SARS-CoV-2 demonstrated that both SARS-CoV and SARS-CoV-2 have an almost identical receptor-binding domain (RBD) in the spike protein of the virus envelope that is used to bind to cellular receptors. ${ }^{13,28}$ Human ACE2 recognises this viral RBD and this is the mechanism by which SARS-CoV-2 enters human cells to facilitate viral replication. ${ }^{13,29}$ Studies of SARS-CoV in mice showed that the severity of ARDS was dependent on the degree of viral replication and the host's immune response to the virus. ${ }^{27}$ The degree of viral replication in the cases presented can be assumed to be low because the patients did not demonstrate signs or symptoms of ARDS. The patient in Case Three also failed to develop immunoglobulins against the virus. SARS-CoV was also found to downregulate ACE2, resulting in more severe ARDS in mice. ${ }^{27}$ Only one patient described above, Case Two, underwent medical imaging during the course of their illness, which did not demonstrate ARDS.

One study analysed genomic databases and employed a structural model programme to observe how the SARS-CoV-2 RBD interacts with various allelic variants of ACE2.30 The study identified 17 allelic variants which interacted with virus RBD; some of these variants were shown to have a stronger affinity for binding to SARSCoV-2, whereas some were identified to have very weak affinity for binding, thus conferring some resistance to binding with SARS-CoV-2. It is likely that the infected patients in this study's cases carried allelic variants that bound weakly to SARS-CoV-2, which resulted in either asymptomatic or mild-to-moderate illness. A total of four males from families with known positive COVID-19 cases tested negative, which likely can be explained by an inherited allele that prevented strong binding between ACE2 and SARS-CoV-2 and thus rendered these patients resistant to infection. Knowledge of whether the ACE2 gene inheritance pattern is dominant or recessive could explain why the adult males in the families of the patients described were negative for infection.

The $\mathrm{X}$ chromosome is known to play an important role in immunocompetence via a few different genetic mechanisms, including coding for tolllike receptors (TLR) and activated cytokine modulators, while also carrying $10 \%$ of the total genomic microRNA. ${ }^{30}$ Socioeconomic factors, behavioural factors, and sex hormones also contribute to males having an overall decreased immunity compared to females. ${ }^{31} \mathrm{~A}$ combination of these genetic and environmental factors therefore accounts for the ability of females to mount a larger immune response compared to males. ${ }^{31}$ This sex-based variation in immune response may account for why more females than males died during the influenza pandemic of the 1920s. ${ }^{32}$ The patient described in Case One received her annual influenza vaccine, which makes it more likely that her reported illness was indeed caused by SARS-CoV-2 infection.

In addition to this sex-based distinction in immunocompetence, the $X$ chromosome is also linked to SARS-CoV-2 viral infectivity through the $A R$ gene which is located on the $X$ chromosome at $X q 12 . .^{15}$ The AR is encoded by the AR gene, and regulates the transcription of transmembrane protease serine 2 (TMPRSS2), which interacts with the SARS-CoV-2 spike protein and primes it for binding with ACE2.15 TMPRSS2 also cleaves the SARS-CoV-2 spike protein in such a way that neutralising antibodies targeting the spike protein are no longer as effective and the host's propensity to resist the SARS-CoV-2 is diminished. ${ }^{15}$ Androgens activate the AR gene to enable promotion of TMPRSS2 transcription, and thus play a role in increased SARS-CoV-2 viral load and reduced potential for fast recovery. ${ }^{15}$

During the current SARS-CoV-2 pandemic there is no significant difference in infection rates between sexes; however, there is increased morbidity and mortality in males compared to females. ${ }^{33}$ It is clearly observed that the affected male patient in Case Two suffered more severe illness requiring medical attention at an ED, while the affected female patients in Cases One and Three were less severely affected.

SARS-CoV-2 spreads rapidly within family clusters, with observational data showing that each family had one primarily infected member and the severity and presentation of illness varied among those infected. ${ }^{33}$ IIIness severity ranged from asymptomatic illness to death, and each member had varied latent periods and durations of viral shedding. ${ }^{34}$ Data also demonstrated that being present in the same room allowed for transmission of infection 
between mildly symptomatic and noninfected individuals. $^{34}$ The patient in Case Two most likely infected his daughter, presented in Case Three. Asymptomatic family members have been known to transmit infection to other members who go on to become symptomatic, with some requiring hospitalisation. ${ }^{35}$ Children in families with infected members either tested negative on PCR, or had mild illness with a shorter duration of viral shedding compared to adults who tested positive in the same house; this pattern is also seen in Case One. It remains unknown whether viable virus shedding extends throughout the period during which members tested positive on the PCR test. ${ }^{35}$ All the cases presented tested positive many weeks after their last reported symptomatic illness.

\section{CONCLUSION}

Upon analysis of this series of cases it appears that the ACE2 gene is inherited in an X-linked, recessive manner, although the sample size is not large enough to categorically conclude this pattern of inheritance. The female patients described in the cases were either asymptomatic or less severely affected than the male patients. $X$ chromosome inactivation is poorly understood and could contribute to the observed sex-biased disease patterns seen in COVID-19.

It is known that the $\mathrm{X}$ chromosome is linked to SARS-CoV-2 viral infectivity through the $A R$ gene, which is located on the $X$ chromosome, and that $A C E 2$ has an unconfirmed pattern of $X$-linked inheritance of its allelic variants, some of which are known to afford stronger binding affinity to SARS-CoV-2. However, there are no studies that investigate these factors in combination with each other, or how this combination predicts disease outcome in males versus females, which would provide a more concrete explanation for the observed pattern that suggests this disease leads to poorer outcomes in males. Investigation of the combination of these factors will allow for greater understanding of the epidemiology of this virus and the development of more accurate guidelines for prevention, diagnosis, management, and prognosis of SARS-CoV-2 infection.

\section{References}

1. Mayo Clinic. Coronavirus disease 2019 (COVID-19). 2020. Available at: https://www.mayoclinic.org/diseasesconditions/coronavirus/symptomscauses/syc-20479963. Last accessed: $20^{\text {th }}$ May 2020

2. Jiang $S$ et al. Neutralizing antibodies against SARS-CoV-2 and other human coronaviruses. Trends Immunol. 2020;41(5):355-9.

3. World Health Organization (WHO). Coronavirus disease 2019 (COVID-19) Situation Report - 73. 2020. Available at: https://www.who.int/ docs/default-source/coronaviruse/ situation-reports/20200402-sitrep73-covid-19.pdf?sfvrsn=5ae25bc7_6. Last accessed: $27^{\text {th }}$ June 2020.

4. World Health Organization (WHO). Criteria for releasing COVID-19 patients from isolation. 2020. Available at: https://www.who. int/news-room/commentaries/ detail/criteria-for-releasing-covid19-patients-from-isolation. Last accessed: $27^{\text {th }}$ June 2020 .

5. Guang $W$ et al. Clinical characteristics of coronavirus disease 2019 in China. N Engl J Med 2020;382(18):1708-20.

6. Centers for Disease Control and Prevention. Coronavirus disease 2019: symptoms. 2020. Available at: https:// www.cdc.gov/coronavirus/2019-ncov/ symptoms-testing/symptoms.html. Last accessed: $27^{\text {th }}$ June 2020.

7. Coperchini et al. The cytokine storm in COVID-19: an overview of the in-volvement of the chemokine/ chemokine-receptor system. Cytokine Growth F R. 2020;53:25-32.

8. National Institutes of Health (NIH). Overview and spectrum of COVID-19. 2020. Available at: https:// covid19treatmentguidelines.nih.gov/ overview/. Last accessed: $20^{\text {th }}$ May 2020.

9. Becker R. COVID-19 update: Covid-19associated coagulopathy. J Thromb Thrombolysis. 2020;50(1):54-67.

10. Morawska L, Cao J. Airborne transmission of SARS-CoV-2: the world should face the reality. Environ Int. 2020;139:105730.

11. Jordan $\mathrm{R}$ et al. COVID-19: risk factors for severe disease and death. BMJ. 2020;368:m1198.

12. Centers for Disease Control and Prevention (CDC). Weekly updates by select demographic and geographic characteristics. 2020. Available at: https://www.cdc.gov/nchs/nvss/vsrr/
covid_weekly/index.htm\#AgeAndSex. Last accessed: $27^{\text {th }}$ June 2020.

13. Zhang $\mathrm{H}$ et al. Angiotensin-converting enzyme 2 (ACE2) as a SARS-COV-2 receptor: molecular mechanisms and potential therapeutic target. Intens Care Med. 2020;46(4):586-90.

14. National Center for Biotechnology Information (NCBI). Gene: angiotensin I con-verting enzyme 2 [Homo sapiens (human)]. Available at: https://www.ncbi.nlm.nih.gov/ gene/59272\#gene-expression. Last accessed: $20^{\text {th }}$ May 2020.

15. Wambier $\mathrm{C}$ et al. Androgen sensitivity gateway to COVID-19 disease severity. Drug Dev Res. 2020;10.1002/ ddr.21688. Online ahead of print.

16. Centers for Disease Control and Prevention (CDC). Coronavirus disease 2019: therapeutic options. 2020. Available at: https://www. cdc.gov/coronavirus/2019-ncov/ hcp/therapeutic-options.html. Last accessed: $20^{\text {th }}$ May 2020.

17. World Health Organization (WHO) "Solidarity" clinical trial for COVID-19 treat-ments. 2020. Available at: https://www.who.int/emergencies/ diseases/novel-coronavirus-2019/ global-research-on-novel- 
coronavirus-2019-ncov/solidarityclinical-trial-for-covid-19-treatments. Last accessed: $27^{\text {th }}$ June 2020.

18. U.S. National Library of Medicine (NLM). Randomised Evaluation of COVID-19 Therapy (RECOVERY). 2020. Available at: https:// clinicaltrials.gov/ct2/show/ NCTO4381936. Last accessed: $27^{\text {th }}$ June 2020

19. U.S. National Library of Medicine (NLM). Trial of treatments for COVID-19 in hospitalized adults (DisCoVeRy). 2020. Available at https://clinicaltrials.gov/ct2/show/ NCTO4315948. Last accessed: $27^{\text {th }}$ June 2020.

20. Centers for Disease Control and Prevention (CDC). Coronavirus disease 2019: protect yourself. 2020. Available at: https://www.cdc.gov/ coronavirus/2019-ncov/preventgetting-sick/prevention.html. Last accessed: $27^{\text {th }}$ June 2020 .

21. EU Clinical Trials Register Investigating a vaccine against COVID-19. 2020. Available at: https:// www.clinicaltrialsregister.eu/ctrsearch/trial/2020-001228-32/GB Last accessed: $27^{\text {th }}$ June 2020 .

22. Centers for Disease Control and Prevention (CDC). Coronavirus disease 2019: Cases, data, \& surveillance. 2020. Available at: https://www.cdc.gov/ coronavirus/2019-ncov/covid-da-ta/ covidview/index.html?CDC AA refVal=https\%3A\%2F\%2Fwww. cdc.gov\%2Fcoronavirus\%2F2019-
ncov\%2Fcovid-data\%2Fcovidview. html. Last accessed: $20^{\text {th }}$ May 2020.

23. Centers for Disease Control and Prevention (CDC). Coronavirus disease 2019: emergency department visits percentage of visits for COVID-19-Like Illness (CLI) or influenza-like Illness (ILI). 2020. Available at: https://www.cdc.gov/ coronavirus/2019-ncov/covid-data/ covidview/05082020/covid-likeillness.html. Last accessed: 20 May 2020.

24. Johns Hopkins University of Medicine. COVID-19 dashboard by the Center for Systems Science and Engineering (CSSE) at Johns Hopkins University (JHU). Available at: https:// coronavirus.jhu.edu/map.html. Last accessed: $27^{\text {th }}$ June 2020

25. Donoghue $\mathrm{M}$ et al. A novel angiotensin-converting enzymerelated carboxypeptidase (ACE2) converts angiotensin I to angiotensin 1-9. Circ Res. 2000;87(5):E1-9.

26. Helix. Cirulli L, Washington $\mathrm{N}$. Revealing variants in SARS-CoV-2 interaction domain of ACE2 and loss of function intolerance through analysis of $>200,000$ exomes. 2020 Available at: https://blog.helix.com/ ace2-sars-cov-2-covid19-exome/. Last accessed: $20^{\text {th }}$ May 2020

27. Kuba $\mathrm{K}$ et al. Multiple functions of angiotensin-converting enzyme 2 and its relevance in cardiovascular diseases. Circ J. 2013;77(2):301-8
28. Lan J et al. Structure of the SARSCoV-2 spike receptor-binding domain bound to the ACE2 receptor. Nature. 2020;581(7807):215-20.

29. Wan $Y$ et al. Receptor recognition by the novel coronavirus from Wuhan: an analysis based on decade-long structural studies of SARS Coronavirus. J Virol. 2020;94(7):e00127-20.

30. Hussain M et al. Structural variations in human ACE2 may influence its binding with SARS-CoV-2 spike protein. J Med Virol. 2020;10.1002/ jmv.25832. Online ahead of print.

31. Schurz $\mathrm{H}$ et al. The $\mathrm{X}$ chromosome and sex-specific effects in infectious disease susceptibility. Hum Genomics. 2019;13(1):2

32. Klein S et al. Mechanisms of sex disparities in influenza pathogenesis. J Leukoc Biol. 2012;92(1):67-73.

33. Wenham $C$ et al. COVID-19: the gendered impacts of the outbreak Lancet. 2020;395(10227):846-8.

34. Song $\mathrm{R}$ et al. Clinical and epidemiological features of COVID-19 family clusters in Beijing, China. J Infect. 2020;S0163-4453(20)30229-2.

35. Zhang $\mathrm{J}$ et al. Familial cluster of COVID-19 infection from an asymptomatic. Crit Care. 2020;24(1):119 